\title{
Psychosocial Factors Influencing Substance Abuse among Undergraduates
}

\author{
Bukunmi. O. Adewumi \\ Department of Psychology, \\ Faculty of Social Sciences, Ekiti State University \\ Ado Ekiti, Ekiti State, Nigeria \\ E-mail: adewumibukunmi@gmail.com
}

\begin{abstract}
This study investigated the psychosocial factors influencing substance abuse among undergraduates. The study was conducted in Ekiti State university Ado Ekiti. 150 participants who are undergraduates of the university were used in this research. They consist of 82 males and 68 females selected from all faculties in the institution. 3 questionnaires were administered to respondent to measure the factors influencing substance abuse and the level at which they are abused. Independent T-test, multiple regression and Pearson Correlation method were used to analyze the data collected. Five hypotheses were tested: hypothesis 1,2, 3 and 4 were significant while hypothesis 5 was insignificant. It was observed that there was significant influence of religiosity on substance abuse among undergraduates, the result also revealed that there was a significant influence of self-esteem on substance abuse among undergraduates, it also revealed that religiosity and self-esteem jointly predicted substance abuse among undergraduates, likewise the result also show that there was significant influence of sex on substance abuse among undergraduates and finally the result revealed there was no significant relationship between religiosity and self-esteem among undergraduates. The results were discussed in line with relevant empirical literatures, while conclusion and recommendations subsequently followed.
\end{abstract}

Keywords: psychopharmacology; mental health; addiction; biopsychology

\section{INTRODUCTION}

Substance abuse is the use of substance/sedate in a wrong way, to such an extent that it misshapes the physical and mental functioning of the abuser. Drug could likewise be abused when it isn't pharmacologically essential and when it is utilized as a part of the substance of legitimate restriction. 
According to Abdullahi (2005), substance abuse has been subjected to various definitions and understandings by various individuals from alternate points of view. These account for variety of implications given to it in the literature. With the end goal of this research, the specialist sees substance abuse as the utilization of any substance for the reasons other than that for which it is ordinarily endorsed or prescribed by a therapeutic professional or organization. It has been watched that greater part of substance abuse begin amid the pre-adulthood arrange, particularly so far the 'passage' medications, liquor and cigarettes, this conveyed the need to check this awful practice in the colleges grounds. Alcohol and cigarettes are depicted as 'door' since they are as a rule, the primary substances that are utilized before different substances are gone for (Indian Preventive Resource Center, 2003). As per Okaza and Aluede (2009) substance abuse by students can prompt sharp decrease in student's scholarly execution, increment reports of truancy and ejection from school. It can likewise prompt fixation (expanded want for drugs without which ordinary life forms is exasperates), and expanded craving and charisma. Social indecencies, for example, taking, battling and assaulting may likewise be caused by substance abuse because of change in the brain of the abusers. Proceeded with abuse of substance over a drawn out timeframe frequently prompts tranquilize resilience and physiological response in which the body requires bigger measurements keeping in mind the end goal to encounter similar impacts (Baron and Kalsher, 2008). Examples of substance abuse may shift incredibly around the globe and extra time. In the United States, the utilization of numerous cognizant modifying substance expanded in the 1990s (Baron and Kalsher). As indicated by Ekey (1997) and Fatoye and Morakinyo (1997), the abuse of substance turned out to be extremely wild in Nigeria in the 1990s. This demonstrates from 1990s to date, there is expanded in tranquilize

The present pattern of substance abuse among youth is a noteworthy national concern, it is disturbing, it affects youth, for example, wellbeing and behavioural issues, or even demise. Falco (1988); as referred to by Sambo (2008) saw that "endless utilization of substance can cause serious, and sometimes irreversible harm to teenagers' physical and mental development. Along these lines, the issue of substance manhandle has moved toward becoming a worrisome wonder, since youth are passing on ethically, socially, mentally and physically. Right now, drugs running from liquor, cigarettes, marijuana, cocaine, heroin to hashish and numerous others are promptly accessible to youth in Nigeria and this has made numerous adolescents to be culprits of social indecencies in the general public.

Mersy (2003) depicted substance abuse as dangerous utilization of liquor, tobacco, or illegal and/or professionally prescribed medications and it has been alluded to as country's main medical issue. While, David, Derald \& Stanley (1990) alludes to substance manhandle as an obsessive example or inordinate use, intake of a substance despite the fact that it might cause physical harm, risking security, (for example, driving 
an auto while inebriated) or disabling social connections and word related working. Requirement for substance may prompt a pre-occupation with its securing and utilize.

Substance abuse may decrease undergrad odds of moving on from school or of finding and holding a stable employment, it might likewise be causing student distress in the grounds which will exasperate scholastic timetable and this may likewise prompt poor scholarly execution. As indicated by Hawkins, Cataland and Miller (1992) a low level of sense of duty regarding training and higher truancy rates have all the earmarks of being identified with substance use among immature. Authority of Justice Statistics (1992) placed that psychological and behavioral issues experienced by liquor and medication utilizing youth may meddle with their scholarly execution and furthermore introduce snags to learning for their colleagues.

Substance abuse is regular among college student; a considerable lot of them abuse substance, for example, sedate liquor and tobacco. Liquor is the most generally utilized and abused sedate among youth, and it causes serious and conceivably perilous issues for this populace. Squeeze Jumba (1991) takes note of that liquor is the most manhandled substance in Nigerian grounds. Denga in Piwana and Haggai (2007) calls attention to that liquor has turned into a recreational past time with students, to the degree that students have discovered another religion in which drinking liquor is the real ceremony. This alludes to the Kegites" Fraternity. The discoveries of Piwana and Haggai (2007) additionally uncovered that the medications generally utilized at religion gatherings incorporate as a matter of first importance liquor and tobacco; all clique bunches abused these two medications frequently.

Self-esteem, is simply the positive or negative assessments of the self, as by the way we feel about it. Self-esteem mirrors a man's general subjective passionate assessment of his or her own value. It is a judgment of oneself and in addition a demeanor toward the self. Self-esteem envelops convictions (for instance, "I am skillful", "I am commendable") and feelings, for example, triumph, depression, pride, and disgrace. Self-esteem discusses the convictions you have about yourself - what you consider the sort of individual you are, your capacities, the positive and negative things about you and what you expect for your future. On the off chance that you have solid self-esteem, your convictions about yourself will by and large be sure. You may encounter troublesome circumstances throughout your life, yet you will by and large have the capacity to manage these without them having excessively of a long haul negative effect on you. On the off chance that you have low self-esteem, your convictions about yourself will regularly be negative. You will tend to concentrate on your shortcomings or mix-ups that you have made, and may think that it is difficult to perceive the constructive parts of your identity. You may likewise point the finger at yourself for any challenges or disappointments that you have. 


\section{Self-esteem and Substance Use}

In Glindemann, Geller and Fortney (1999), specialists suggested that low selfesteem may be a spark for a high utilization of liquor among developing grown-ups. As said some time recently, self-esteem has been regularly characterized as the degree to which one has good or negative self-assessments. One investigation by Parish and Parish (1991) presumed that individuals with low self-esteem are significantly more prone to expend liquor as an approach to attempt to increase some level of companion support and acknowledgment. Likewise low self-esteem impacts the utilization of liquor since liquor gives defense to awful execution or enhances positive sentiments of self-esteem. In Chen, Dufour \& Yi (2004-05) it was discovered that drinking more than the suggested per event most extreme (in undergrads) was probably going to hinder mental execution and might help clarify expanded negative outcomes, for example, poor self-esteem. It has been accounted for that people might utilize liquor to adapt to strain or nervousness since they trust that liquor can create an impact of unwinding and a reduction in tension, and this conviction is particularly held a for people with low self-esteem (Pullen, 1994). Likewise substance use appears to rise when youthful grown-ups have low self-esteem and can't adapt to worry in love positive way.

Religiosity bargains more with how religious a man is, and less with how a man is religious (in rehearsing certain rituals, retelling certain stories, venerating certain images, or tolerating certain regulations about gods and life following death). The terms religiousness/religiosity are utilized conversely however frequently characterized as a person's conviction, dedication, and worship towards a heavenly nature. Be that as it may, in its most far reaching use, religiosity can embody all measurements of religion, yet the idea can likewise be utilized as a part of a limited sense to indicate an outrageous view and over devotion to religious ceremonies and customs. This inflexible type of religiosity generally is frequently seen as a negative side of the religious experience, it can be encapsulated by an over association in religious practices which are esteemed to be past the social standards of self-esteem.

\section{Religiosity and Substance Abuse}

Spearheading the exploration into the religiosity/misconduct relationship were Hirschi and Stark (1969), who anticipated that through social control, church participation would diminish adolescent wrongdoing. Strikingly, they neglected to discover a connection amongst religiosity and wrongdoing. Nonetheless, it is conceivable that the measures of religiosity utilized (adolescent church participation and self-esteem in the great beyond) did not truly or enough measure religiosity, particularly since adolescent religiosity can be bewildered by different impacts (Evans et al., 1995).

The last measure may have likewise been exceptional named an otherworldly measure. Hirschi and Stark's finding that religiosity was not related with less incessant misconduct gave the driving force to explore in to the impacts of religion on criminal and 
freak practices (Evans et al., 1995), which has already talked about has been to some degree ailing in hypothetical development, even recent studies. Other later examinations have inspected religiosity and substance abuse.

Mill operator (1998) found a noteworthy connection between people with liquor and medication issues and a present absence of religious association or investment. Pullen et al. (1999) found a comparative connection between chapel participation and medication and liquor use in adolescents. In like manner, in an investigation of internal city crisis room patients, Bazargan et al. (2004) found that among a few religious measures, religious investment was identified with not including utilized liquor inside six hours of affirmation and furthermore with restraint from liquor utilize, while no affiliation was found with different religious/otherworldly measures. Michalak, Trocki, and Bond (2007) investigated the connection amongst religion and drinking practices through an auxiliary examination of the 2000 National Alcohol Survey and found that drinking practices, particularly add up to forbearance, were fundamentally related to measures of religiosity. Mill operator (1998) found that "religiously included people are reliably less inclined to utilize liquor and different medications, and when they do as such are more averse to take part in overwhelming use and endure its unfavorable outcomes" (pp. 981-982). This announcement was a decent summation of many research discoveries that gave prove that religiosity is related with a reduced probability of participating in substance manhandling practices.

\section{Statement of the Problem}

Unlawful medication utilize is harmful to the two people and the general public, generating violations, spreading sicknesses like AIDS, executing our adolescents and future pioneers. Today, there are evaluated 90 million medication clients around the globe and no nation alone can stem the medication exchange inside its outskirts. No nation is resistant and no individual truly is (Awake, July 8, 2001).

A few people are engaged with the utilization of unlawful medications since they need to lessen normal weights around them, to conceal for their low self-esteem. It symbolizes a dissent against set principles, and to investigate fundamental to self (Omage, 2005).The capture by police, NDLEA and the news reports uncovered that unlawful medication utilize is on the expansion. The significant worry of this examination along these lines is to distinguish the impact of self-esteem on substance abuse among undergrad.

In spite of the impact of many concerned bodies to check this danger, many people still present these medications as if they are innocuous. They give them motto, for example, "for enormity", "for taste" and so forth which frequently bait silly young people 
into medications and liquor abuse and long haul impacts of the abuse of medication on themselves, their families and the general public on the loose.

Religiosity has additionally been related with positive medication related results. It can ensure young people against substance use in various ways. It might repress juvenile hazard conduct by modifying conduct affecting esteems or by working as an outside control factor (Amoateng\& Bahr, 1986). A few religions unequivocally restrict substance utilize. Another worry of this investigation is the impact of religiosity on substance manhandle. A few people additionally trust that male immature tends to manhandle drugs than female, along these lines; influencing this examination to be keen on knowing the impact of sex on substance to abuse.

\section{Purpose of the Study}

This study involve the analysis of psychosocial variable that influence substance abuse among undergraduates. It will also find out the effect of sex on substance abuse among undergraduates.

Specifically the aims of the study are:

1) To find out whether religiosity will have significant influence on substance abuse.

2) To verify whether or not self esteem as a psychosocial factor will have effect on substance abuse.

3) To determine whether sex will have significant influence on substance abuse or not.

4) To verify whether or not self-esteem and religiosity will jointly predict substance abuse.

5) To investigate if there will be a significant relationship between religiosity and selfesteem among undergraduates.

\section{Relevance of the Study}

It is not just enough to acknowledge the fact that a problem exist but also device means and methods of knowing the root cause and eradication of such problems.

This project is relevant to knowing the health status and the pattern of drug use among undergraduates. The findings obtained from this study will advance our knowledge about the mental and behavioural functioning of undergraduates who use drugs.

The findings of these studies would help to understand and create awareness about what young adults are experiencing and as well involving themselves in, at college and to provide specific suggestion for parents and family as well help undergraduates to be successful. 


\section{Scope of the Study}

Specifically, this work is designed to capture and analyze the influence of selfesteem, religiosity and sex on substance abuse and this is purposively limited to the undergraduates at Ekiti state university, Ado-Ekiti state. Data on self-esteem, religiosity, and substance abuse will be collected by administering standardized questionnaires to the respondents.

This study will not digress from it proposed domain in order to reduce entanglement and excess use of words. This research will avoid any form of bias. The result obtained will be used to generalize the assessment of psychosocial factors influencing substance abuse among undergraduates in Ekiti state university.

\section{LITERATURE REVIEW AND THEORETICAL FRAMEWORK THEORETICAL FRAMEWORK Social Learning Theory}

According to Bandura (1977), people observe others behaviours, and outcomes of those behaviours. This theory holds that behaviour is moulded by rewards and punishments or reinforcement.

Social learning theory has a clear-cut application to drug use. It proposes that the use of drugs or psychoactive substances can be explained by different exposure to groups in which drug use is rewarded. The definitions are learned through imitation and social reinforcement by members of the group with whom 'me' is associated (Akers, 1992). Drug use, is determined "by the extent to which a given pattern of behaviour is sustained by the combination of the reinforcing effects of the substance with social reinforcement, definitions through bad effects of the substance and or the negative sanctions from peers, parents, and the law" (Akers et al, 1979).

Social learning theory, then, proposes that the extent to which drugs will be used depends on the extent to which the behaviour has been differentially reinforced. Moreso, parental characteristics and behaviours of family members like parental substance or drug use, criminal conduct, and incarceration are associated with drug use among undergraduates. Parental use of drugs and cigarettes has been shown to transmit across generations (Wu \&Kandel, 1995).

\section{Biological Theory}

Biological theory holds that certain behaviours are primarily due to a person's biochemistry, metabolism and genetic predisposition. Biological theory postulates that specific physical mechanisms in individuals that impel or influence them to experiment with drugs or to abuse them once they are exposed to them. Some are constitutional, that 
is, are based on mechanisms that are present at birth and vary from one person to another. Others are partly environmental; that is, inborn factors in conjunction with environmental factors generate drug using behavioral pattern.

Biological theory explains that the genetic make-up of individuals predisposes them toward drug use. A gene or combination of genes influences the biological mechanisms relevant to substance use such as being able to achieve a certain level of intoxication when using dru8gs, becoming ill at low doses, or having the capacity to metabolize chemical substances in the body. This level of genetic loading in combination with environmental and personality factors could make for a significantly higher level of drug use in certain individuals or groups in the population.

\section{Social Comparison Theory}

Social comparison theory is a theory that can be used to explain self-esteem. It was first proposed in 1954 by psychologist Leon Festinger. He believed we engaged in this comparison process as a way of establishing a benchmark by which we can make accurate evaluations of ourselves and learn how to define self, this definition of self can either increases self-esteem or lower it. For example, a music student might compare herself to the intelligent student in her class, if she finds that her own abilities do not measure up to her peer's talents, she might be driven to achieve more and improve her own abilities, self-beliefs and self-esteem. The social comparison process involves people coming to know their effectiveness, capacity and self-esteem by evaluating their own attitudes, abilities, and beliefs through comparison with others.

Self-Evaluation: According to Thorton and Arrowood (1966). Self-evaluation is one of the functions of social comparison. This process underlines how an individual compares him or herself with others to determine and certify his ability, capacity, self-beliefs, it is when this person have compared himself or herself with others, that he can properly define self. (Thorton\&Arrowood 1966) Each individual's specific goals will influence how they engage in social comparison target that is similar to them (Wood, J.V. 1989). Specifically, they are most interested in choosing a target who shares some distinctive characteristics with themselves.

Self-Enhancement: Individuals may also seek self-enhancement, or to improve their self-esteem. They may interpret, distort, or ignore the information gained by social comparison to see them more positively and further their self-enhancement goals. They will also choose to make upward (comparing themselves to someone better off) or downward (comparing themselves to someone worse off) comparison, depending on which strategy will further their self-enhancement goals. They may also avoid making certain types of comparisons. Specifically, when an individual believes that their ability in a specific area is low, they will avoid making upward social comparisons in that area. Unlike for self-evaluation goals, people engaging in social comparison with the goal of 
self-enhancement may not seek out target that are similar to themselves. In fact, if a target outperforms the individual on some dimensions, the individual may downplay the similarity of the target to themselves.

\section{Upward and Downward Social Comparisons}

Wills introduced the concept of downward comparison in 1981. Downward social comparison is a defensive tendency that is used as a means of increasing one's selfesteem through comparison with others. When a person looks to another individual or group that they consider being worse off than themselves in order to feel better about their self or personal situation, they are making a downward social comparison.

Upward social comparison are made to self-evaluate and self improve in the hopes that self enhancement will also occur. This is when an individual compares himself or herself with others greater than them to feel better about their self and realize their selves. In an upward social comparison, people want to believe themselves to be part of the elite or superior, and make comparison, highlighting the similarities between themselves and the comparison group, unlike a downward social comparison, where similarities between individuals or groups are dissociated.

\section{Self-Derogatory Theory}

This theory explains that there is something wrong in the emotional or psychic life of certain individuals that makes drugs attractive to therm. They use drugs as an escape from reality, as a means of avoiding life's problems. Not all undergraduates that use drug share personality inadequacies and impaired mental functioning to an exact extent; some will even feel the peer pressure to used substances. Nevertheless, as the personality seems inadequate, the greater the likelihood of becoming highly involved with drug use and the more the use becomes abuse. The usage of drugs by undergraduates is an adaptation of a defense mechanism, to cater for feelings of inferiority that arose from the deficiencies in their personality make-up.

\section{RELATED EMPERICAL STUDIES}

Alcohol use is prevalent among adolescents, with initiation of use occurring at a younger age and amount of use increasing as the child ages. Approximately $80 \%$ of adolescents in $12^{\text {th }}$ grade and $50 \%$ of $8^{\text {th }}$ graders have used alcohol at least once with $30 \%$ and $12 \%$ respectively, engaging in binge drinking (SAMHSA, 2002). The use of illicit drugs, in particular marijuana, is increasing in adolescent due to a decline in perceived risk. Apparently, it was confirmed that there is a $12 \%$ increase in use by $8^{\text {th }}$ graders from 1991 to 2002 (SAMHSA, 2002; Johnson, O’malley, \& Bachman, 2003). Approximately $40 \%$ of adolescents in grades 9-12 reported that they used tobacco (HHS, 2000). Formerly depressed children who experience depression or substance abuse disorder 
recurrently within 5 years show impairments in psychological functioning, social adjustment and low awful quality of life (Lewinsohn, et al. 2003). Initiation of substance abuse can occur at an early age and continue throughout adolescence (Schiffman, 2004). Per a literature by Schiffman (2004) substance also appears to co-occur with other term effects reported to be associated with ongoing adolescent substance abuse include both cognitive and physical health problems in adulthood (Brook, Finch, Whiteman, \& Brook, 2002).

In a study by Samuels (1974), scientists discovered that low self-concept was chosen as a major motive for (not source of) adolescents' substance use. In the college population, it has been found that heavy drinkers have lower self-concepts than light or moderate drinkers. Segal, Rhenberg, and Sterling (1975) discovered that among female college students, substance users had the lowest self-concept scores. Some evidence indicates that heavy drinking is associated with females with low self-esteem, and the opposite might be true for males. Research in this study indicates that patterns of selfesteem for males and females are different. Females may be at greater risk for low selfesteem associated with heavy consumption of alcohol. Segal et al. (1975) found that with the female college population, those who abstained had more positive self-esteem than substance users. It has been found that many students deal with self-esteem issues by engaging in negative health behaviors. Recently researchers (Sands, Archer \& Puelo, 1998) have found that low self-esteem predicted alcohol abuse problems. In response to the extreme stress that college students' experience, which has shown a dramatic increase in the last 30 years, students often engage in negative health behaviors such as drinking and smoking. As other researchers have found, individuals with low self-esteem seemed to have more physical health problems. It was not found, however in this study, that there actually was a relation between self-esteem and alcohol usage (Pritchard, Wilson, \& Yamnitz, 2007).

As previously stated, some researchers have offered that low self-esteem might be a motivator for consuming high levels of alcohol, and we know that self-esteem is derived from subjective evaluations that people make about their own behavioral traits and can also be defined as the extent to which our self-evaluations are favorable or unfavorable. Certain researchers claim that those students with low self-esteem are more likely to drink alcohol in an effort to gain peer acceptance and support. Students may drink alcohol because they believe that it can produce a relaxation effect and decrease anxiety levels - and this may be more pronounced for people with low self-esteem, and substance use seems to escalate if students have low self-esteem. In a study conducted by Maney (1990), Rosenberg's (1965) Scale and the Annual Absolute Alcohol Intake Inventory were administered to 443 university students. A significant correlation was found between self-esteem and self-reported drinking using both measures. However, the study did not find a significant correlation between self-esteem scores and self-reported 
measure of the total amount of alcohol consumed by respondents (as cited in Glindemann et al., 1999).

In the opinion of Wang and Veugelers (2008), self-esteem is an important determinant of adolescent mental health and development. Dolcini and Adler's (1994) placed the relationship between peer substance use and self-esteem within the context of peer groups. Both earlier and later studies (Liem et al., 2010; Withya et al., 2007) have found significant negative correlations between self-esteem and substance abuse among adolescents. In a study conducted by James (2003), a significant negative correlation was found between self-esteem and substance abuse. However, Taylor and DelPilar (1992) in an earlier study conducted among adolescents in the 90's found a significant and positive correlation between self- esteem and substance abuse. Schroeder, Laflin and Weis (1993) contend that although relationships has been found between self-esteem and substance abuse among scholars, however these relationships were not sizable, hence implying it should be interpreted with caution.

In the submission of Zamboanga et al (2009), self-esteem is the most consistent predictor of the likelihood and extent of substance abuse. Available evidence therefore suggests that low self-esteem and peer influence contribute to adolescent alcohol abuse (Radin et al., 2006). In consonance with the above findings, Withya et al. (2007) revealed that one of the causes of substance abuse include low self-esteem. On the other hand, Kumpulainen and Roine (2002) noted that low self-esteem was potentially connected to later substance use. In the submission of De Bruijn, Kremers, van Mechelen and Brug (2005) self-esteem is one of the constructs with the ability to hamper or increase health behaviors'.

Other researchers have explored the behavioral dimension of religiosity alone, defining it in terms of religious activities, such as frequency of church attendance and conversations with a religious leader (Neff \& Hope, 1993; Zimmerman \& Maton, 1992). Others have distinguished between private and public religious behavior: Private religiosity refers to personal prayers, the study of religious texts, and the individual effort to live by religious standards, whereas public religiosity refers to attendance at religious services, public prayer, and participation in group religious activities (Bahr, Maughan, Marcos, \& Li, 1998; Hill, 2000). Under a behavioral conceptualization of religiosity, a person is more religious if he or she is more involved in religious activity, such as prayer and ceremonial worship, and/or in religion-related activity, such as faith youth groups and religious scholarship.

Researchers exploring the attitudinal dimension of religiosity have conceptualized it as the degree to which a person expresses sincere and earnest regard for religion (Cochran, 1993) and as the extent to which an individual agrees or disagrees with certain statements regarding religious ideals (Patock-Peckham, Hutchinson, Cheong, \& Nagoshi, 
1998). Others have defined it in terms of spirituality (Hodge, Cardenas, \& Montoya, 2001). Under an attitudinal conceptualization of religiosity, a person is more religious if he or she is more committed to the religion, in terms of either the religion's teachings or its personal importance to him or her.

Religiosity has been viewed, for the most part, as an individual-level variable. However, because adolescents are under the authority of their parents, their religious involvement may be dictated by their parents. As Hodge et al. (2001) pointed out, "In cases in which religious participation is seen as an expression of individual spirituality, it may be more likely to express the parents' rather than the adolescent's spirituality".

Many youths may be required, or at least strongly encouraged, to attend religious services as part of a family practice. In such cases, participation in religious services does not reflect an adolescent's spirituality or even a desire to participate in religious activities. Perhaps fsor this reason, some researchers have defined religiosity in terms of family, rather than personal, religiosity (Hardesty \& Kirby, 1995).

\section{Operational Definition of Terms}

The following definitions were adopted for the purpose of this study.

Religiosity: This is defined as the as the consistency of engagement in matters regarding holding of beliefs and religious practices, and this will be measured with Santa Clara Strength of Religious Faith Questionnaire (SCSORF) developed by Plante \& Boccaccini, (1997a,b).

Self-Esteem: This refers to an evaluation of one's self concept, it is a positive or negative orientation towards one's self. An individual could have high social esteem or low self esteem which will be measured with Rosenberg Self-esteem Scale, developed by Rosenberg (1965).

Substance Abuse: this is define as wrongful usage of chemical substance that defy medical prescription and thus harmful to one's health and total well-being and will also be measure with Drug Abuse Screening Test(DAST) scale by Harvey A. Skinner PHD 1982.

Undergraduates: The student in a university who has not received a first, especially a bachelor's degree as represented in this study by Ekiti State University.

\section{Hypotheses}

i. There will be a significant influence of religiosity on substance abuse among undergraduates

ii. There will be a significant influence of self esteem on substance abuse among undergraduates

iii. Religiosity and self-esteem will jointly predict substance abuse among undergraduates 
iv. There will be a significant influence of sex on substance abuse among undergraduates

v. There will be a significant relationship between religiosity and self-esteem among undergraduates.

\section{METHODS}

It is survey because it uses questionnaire in measuring and sampling people's opinion on the influence of religiosity, self-esteem and sex on substance abuse.

\section{Research Participants}

The total numbers of one hundred and fifty (15 0) participants were purposefully selected among Ekiti State University undergraduates.

\section{Variables in this Research}

There are three variables that are involved in this research; we have two independent variables and one dependent variable. The independent variables are: Self-esteem and Religiosity while the dependent variable is substance abuse.

\section{Research Instruments}

Questionnaire comprising of four sections was employed by this study. Section A was designed to collect personal demography data of the research participants, which include sex and religion; Section B comprises of questionnaire measuring Drug abuse, 10 items Drug Abuse Screening Test(DAST) scale by Harvey A. Skinner PHD 1982 which was designed to be used in variety of setting to provide a quick index of drug-related problems; while Section C consisted of 10 item Santa Clara Strength of Religious Faith Questionnaire (SCSORF) by Plante\&Boccaccini, (1997a,b)and 10 items Rosenberg Selfesteem Scale1965 used to understand the general feelings of undergraduates about themselves was clearly stated in section D.

\section{Drug Abuse Screening Test (DAST)}

The Drug Abuse Screening Test (DAST) was designed to be used in various settings to provide a quick index of drug-related problems. The DAST yields a quantitative index of the degree of consequences related to drug abuse. This instrument takes approximately 5 minutes to administer and may be given in questionnaire, interview, or computerized format. The DAST provides a brief self report instrument for population screening, identifying drug problems in clinical settings and treatment evaluation.

Validity: Convergent validity of $r=0.76$ when correlated with the Drug Use Disorders Identification Test (DUDIT)

Reliability: The 10-item DAST has internal consistency reliability of $0.92-0.98$ 
Scoring: Score 1 point for each question answered "Yes," except for question 3 for which a "No" receives 1 point.

\section{Rosenberg Self-Esteem Scale}

The RSE, a 10-item scale, was introduced in 1965 in Rosenberg's study of a large sample of high school students in New York State. Rosenberg intended the instrument to be uni-dimensional, and it was originally presented as a Guttman scale, but it is typically administered using a Likert-type response format, employing4-, 5-, or 7-point scales ranging from Strongly Disagree to Strongly Agree.

\section{Reliability and Validity}

The Rosenberg Self-esteem Scale presented high ratings in reliability areas; internal consistency was 0.77 , minimum coefficient of reproducibility was at least 0.90 (Rosenberg, 1965, and personal communication, April 22, 1987). A varied selection of independent studies each using sample as parents, men over 60 , high school students, and civil servants- showed alpha coefficient ranging from 0.72 to 0.87 ( all fairly high). Testretest reliability for the 2-week interval was calculated at 0.85 , the 7-month interval was calculated at 0.63 (Silber and Tipett, 1965, Shorkey\& Whiteman,1978). The RES is closely connected with the Coopersmith Self-Esteem Inventory.

Scoring: items 2, 5, 6, 8, 9 are reverse scored. Give "Strongly Disagree" 1 point, "Disagree" 2 points, "Agree" 3 points, and "Strongly Agree" 4 points. Sum scores for all ten items. Keep scores on a continuous scale. Higher scores indicate higher self-esteem.

\section{Santa Clara Strength of Religious Faith Questionnaire (SCSORF).}

The Santa Clara Strength of Religious Faith Questionnaire (SCSORF; Plante\&Boccaccini, 1997a,b) is a 10-item self-report measure. It was designed to measure strength of religious faith, regardless of religious denomination or affiliation, for use within both research and clinical contexts. Moreover, it is intended to provide researchers with a quick and easy to administer measure of religiosity. Sample items include 'My religious faith is extremely important to me' (item-1) and 'My relationship with God is extremely important to me' (item-7). The scale uses a 4-point Likert response format, ranging from (1) Strongly disagree to (4) Strongly agree. Scores can range between 10 and 40, with higher aggregate scores reflecting stronger levels of 'Strength of Religious Faith'.

The SCSORF was developed for use among both clinical and non-clinical samples. For example, Plante and Boccaccini, (1997a,b) administered the scale to USA College students. Lewis, Shevlin, McGuckin, and Navrátil (2000) employed the scale among a sample of Northern Irish University students.

Reliability (Internal Consistency): At present little research has examined the reliability of the SCSORF. Plante and Boccaccini $(1997 \mathrm{a}, \mathrm{b})$ found the SCSORF to possess a high 
level of internal consistency, with Cronbach's alphas ranging between .94 and .97 and split-half reliability correlations between .90 and .96 .

\section{Validity}

This scale has a good convergent validity. Plante and Boccaccini (1997a) and Plante, Yancey, Sherman, Guertin, and Partdini(1999) found that higher scores on the SCSORF were significantly associated with higher scores on Plante and Boccaccini's (1997a) newly developed measures of strength of faith, religiousness, spirituality, faith aiding coping, and overall feelings of comfort

Scoring: to score, add the total scores. They will range from 10 (low faith) to 40 (high faith).

\section{RESULTS}

The data collected were scored and analysed. The following are the results:

Table 1: Means (M), Standard Deviations (SD) and Correlations among the Study Variables

\begin{tabular}{|l|l|c|c|}
\hline $\begin{array}{l}\text { Variable } \\
\mathrm{N}=150\end{array}$ & M (SD) & $\mathbf{1}$ & $\mathbf{2}$ \\
\hline 1. Drug abuse & $3.07(2.32)$ & - & \\
\hline 2. Religiosity & $16.59(5.71)$ & $.24^{* *}$ & - \\
\hline 3. Self-esteem & $24.03(6.05)$ & .14 & -.13 \\
\hline${ }^{* *} p<.01(2$-tailed)
\end{tabular}

The result of correlation analyses between study variables are presented in table 1 above. There was a significant positive relationship between religiosity and drug abuse $[r$ $(149)=.24, p=.003]$. However, self-esteem was not statistically related to drug abuse $[r$ $(149)=.14, \mathrm{p}=.09]$. Additionally, religiosity and self-esteem were not related to each other $[r(149)=-.13, p=.12]$.

\section{Hypothesis One}

There will be a significant influence of religiosity on substance abuse among undergraduates.

Table 2: Comparison of mean scores on substance abuse between high and low religiosity

\begin{tabular}{|l|l|l|l|l|l|l|c|}
\hline & \multicolumn{2}{|l|}{$\begin{array}{l}\text { Low } \\
\text { religiosity }\end{array}$} & \multicolumn{2}{l|}{$\begin{array}{l}\text { High } \\
\text { religiosity }\end{array}$} & \multicolumn{2}{l|}{} \\
\hline Variable & M & SD & M & SD & t $_{(\mathbf{1 4 8})}$ & $\mathbf{9 5 \% C I}$ & Cohen's $\boldsymbol{d}$ \\
\hline Drug abuse & 2.57 & 2.19 & 3.79 & 2.31 & $-3.29^{* *}$ & {$[-1.96,-.49]$} & -.55 \\
\hline
\end{tabular}


$* * p<.01$ (2-tailed)

The result in table 2 above shows that difference in drug abuse scores between participants who have low religiosity $(\mathrm{n}=88, \mathrm{M}=2.57, \mathrm{SD}=2.19)$ and high religiosity $(\mathrm{n}=62, \mathrm{M}=3.79, \mathrm{SD}=2.31)$ were statistically significant, $\mathrm{t}(148)=-3.29, \mathrm{p}=.001,95 \%$ CI $[-1.96,-.49], d=-.55$. This means that participants with high religiosity have significantly higher drug abuse scores than their counterparts who are lowly religious with a moderate effect size. Therefore, hypothesis one is supported.

\section{Hypothesis Two}

There will be a significant influence of self-esteem on substance abuse among undergraduates.

Table 3: Comparison of mean scores on substance abuse between high and low religiosity

\begin{tabular}{|l|l|l|l|l|l|l|c|}
\hline & \multicolumn{2}{|l|}{$\begin{array}{l}\text { Low self- } \\
\text { esteem }\end{array}$} & \multicolumn{2}{l|}{$\begin{array}{l}\text { High self- } \\
\text { esteem }\end{array}$} & \multicolumn{2}{l|}{} \\
\hline Variable & M & SD & M & SD & $\mathbf{t}_{(\mathbf{1 4 8})}$ & $\mathbf{9 5 \% C I}$ & Cohen's $\boldsymbol{d}$ \\
\hline Drug abuse & 2.37 & 2.15 & 3.80 & 2.26 & $-3.97 * * *$ & {$[-2.14,-.72]$} & -.65 \\
\hline
\end{tabular}

$* * * p<.0001$ (2-tailed)

The result in table 2 above shows that difference in drug abuse scores between participants who have low self-esteem $(\mathrm{n}=76, \mathrm{M}=2.37, \mathrm{SD}=2.15)$ and high selfesteem $(\mathrm{n}=74, \mathrm{M}=3.80, \mathrm{SD}=2.26)$ were statistically significant, $\mathrm{t}(148)=-3.97, \mathrm{p}<$ $.0001,95 \%$ CI $[-2.14,-.72], d=-.65$. This means that participants with high self-esteem have significantly higher drug abuse scores than their counterparts who have low selfesteem with a moderate effect size. Therefore, hypothesis two is supported.

\section{Hypothesis Three}

Religiosity and self-esteem will jointly predict drug abuse among undergraduates.

Table 4: Regression analysis showing the influence of the independent variables on drug abuse

\begin{tabular}{|l|l|l|l|l|l|l|l|}
\hline Variable & $\boldsymbol{\beta}$ & $\mathbf{T}$ & $\mathbf{p}$ - value & $\mathbf{R}$ & $\mathbf{R}^{\mathbf{2}}$ & $\mathbf{F}$ & p-value \\
\cline { 1 - 4 } Religiosity & .26 & 3.27 & .001 & & & & \\
\cline { 1 - 4 } Self-esteem & .17 & 2.17 & .032 & .29 & .09 & 6.91 & .001 \\
\hline Dependent Variable: Drug abuse
\end{tabular}

$F(2,147)=6.91, \mathrm{p}=.001, R^{2}=.09$

Table 4 showed that religiosity and self-esteem jointly predicted drug abuse $[\mathrm{F}(2,147)=$ 6.91 ,

$\left.\mathrm{p}=.001, \mathrm{R}^{2}=.09\right]$. Additionally, religiosity $[\beta=.26, \mathrm{p}=.001]$ and self-esteem $[\beta=.17, \mathrm{p}$ $=.032]$ had independent influences on drug abuse. Therefore, hypothesis three is supported. 


\section{Hypothesis Four}

There will be a significant influence of sex on substance abuse.

Table 5: Comparison of mean scores on substance abuse between high and low religiosity

\begin{tabular}{|l|l|l|l|l|l|l|c|}
\hline & \multicolumn{3}{|l|}{ Male } & \multicolumn{2}{l|}{ Female } & \multicolumn{2}{l|}{} \\
\hline Variable & M & SD & M & SD & $\mathbf{t}_{(\mathbf{1 4 8})}$ & $\mathbf{9 5 \% C I}$ & Cohen's $\boldsymbol{d}$ \\
\hline Drug abuse & 3.54 & 2.37 & 2.51 & 2.12 & $2.75^{* *}$ & {$[.28,1.76$} & .46 \\
\hline$* * p<01$ (2-tailed)
\end{tabular}

The result in table 5 above showed that difference in drug abuse scores between males ( $\mathrm{n}$ $=82, \mathrm{M}=3.54, \mathrm{SD}=2.37)$ and females $(\mathrm{n}=68, \mathrm{M}=2.51, \mathrm{SD}=2.12)$ were statistically significant, $\mathrm{t}(148)=2.75, \mathrm{p}=.007,95 \%$ CI $[.28,1.7], d=.46$. This means that males have significantly higher drug abuse scores than females with a moderate effect size. Therefore, hypothesis four is supported.

\section{Hypothesis Five}

There will be a significant relationship between religiosity and self esteem among undergraduates.

It is shown in table 1 above that religiosity and self-esteem were not related to each other $[r(149)=-.13, p=.12]$. Therefore, hypothesis five is not supported.

\section{DISCUSSION}

\section{DISCUSSION, CONCLUSION AND RECOMMENDATIONS}

The first hypothesis stated that there will be a significant influence of religiosity on substance abuse among undergraduates, the result shows that difference in drug abuse scores between participants who have low religiosity were statistically significant.

This means that participants with high religiosity have significantly higher drug abuse scores than their counterparts who are lowly religious with a moderate effect size. Therefore, hypothesis one is supported. Some basic reasons might be responsible for the confirmation of this hypothesis, for instance, the Hausas are more often religious and still believe that taking substance is not a sin, since it's not codified in the holy scripture.

Religiosity has been viewed, for the most part, as an individual-level variable. However, because adolescents are under the authority of their parents, their religious involvement may be dictated by their parents. As Hodge et al. (2001) pointed out, "In cases in which participation is seen as an expression of individual spirituality, it may be more likely to express the parents' rather than the adolescent's spirituality". Many youths may be required, or at least strongly encouraged, to attend religious services as part of a 
family practice. In such cases, participation in religious services does not reflect an adolescent's spirituality or even a desire to participate in religious activities. Perhaps for this reason, some researchers have defined religiosity in terms of family, rather than personal, religiosity (Hardesty \& Kirby, 1995).

The second hypothesis stated that there will be a significant influence of selfesteem on substance abuse among undergraduates. The result revealed that participants with high self-esteem have significantly higher drug abuse scores than their counterparts who have low self-esteem with a moderate effect size. Therefore, hypothesis two is supported.

In the opinion of Wang and Veugelers (2008), self-esteem is an important determinant of adolescent mental health and development. Dolcini and Adler's (1994) placed the relationship between peer substance use and self-esteem within the context of peer groups. Both earlier and later studies (Liem et al., 2010; Withya et al., 2007) have found significant negative correlations between self-esteem and substance abuse among adolescents. In a study conducted by James (2003), a significant negative correlation was found between self-esteem and substance abuse. However, Taylor and DelPilar (1992) in an earlier study conducted among adolescents in the 90's found a significant and positive correlation between self- esteem and substance abuse. Schroeder, Laflin and Weis (1993) contend that although relationships has been found between self-esteem and substance abuse among scholars, however these relationships were not sizable, hence implying it should be interpreted with caution.

Hypothesis three which states that religiosity and self-esteem will jointly predict drug abuse among undergraduates. The results gotten from this hypothesis shows that religiosity and self-esteem jointly predicted drug abuse. Therefore, hypothesis three is supported.

In the submission of De Bruijn, Kremers, van Mechelen and Brug (2005) selfesteem is one of the constructs with the ability to hamper or increase health behaviours. It has been found that many students deal with self-esteem issues by engaging in negative health behaviors. Recently researchers (Sands, Archer \&Puelo, 1998) have found that low self-esteem predicted alcohol abuse problems. In response to the extreme stress that college students' experience, which has shown a dramatic increase in the last 30 years, students often engage in negative health behaviors such as drinking and smoking. As other researchers have found, individuals with low self-esteem seemed to have more physical health problems. It was not found, however in this study, that there actually was a relation between self-esteem and alcohol usage (Pritchard, Wilson, \&Yamnitz, 2007).

As previously stated, some researchers have offered that low self-esteem might be a motivator for consuming high levels of alcohol, and we know that self-esteem is derived from subjective evaluations that people make about their own behavioral traits and can also be defined as the extent to which our self-evaluations are favorable or unfavorable. 
In this study, individuals with higher levels of religiosity have higher rates of substance abuse. In contrast to this, numerous studies demonstrate a significant association between religious practice and healthy behavioral habits relating to cigarettes, alcohol, and drugs. Individuals with higher levels of religious involvement have lower rates of abuse and addiction and are more likely to find long-lasting success if they ever struggled with any of these behaviors. In a comprehensive review of the academic literature on religion and substance abuse, Byron Johnson of Baylor University and his colleagues reported that, in the vast majority of studies, participation in religious activities was associated with less drug abuse.

Hypothesis four which state that there will be a significant influence of sex on substance abuse, showed that difference in drug abuse scores between males and females were statistically significant. This means that males have significantly higher drug abuse scores than females with a moderate effect size. Therefore, hypothesis four is supported.

A number of epidemiologic survey studies have demonstrated that the prevalence rates of drug and alcohol use disorders are consistently higher among men than among women. The most recent of these studies, the National Institute on Alcohol Abuse and Alcoholism's National Epidemiologic Survey on Alcohol and Related Conditions (NESARC), surveyed more than 40,000adults and found that men are twice as likely as women to meet lifetime DSM-IV criteria for any drug use disorder $(13.8 \%$ of men vs $7.1 \%$ of women). Twelve-month prevalence rates of alcohol abuse are almost 3 times as high among men as they are among women (6.9\% of men vs $2.6 \%$ of women). These ratios are consistent with the findings of other past epidemiologic surveys, showing that the gender differential for alcohol use disorders is higher than that for drug use disorders

The fifth hypothesis revealed that there will be a significant relationship between religiosity and self-esteem among undergraduates. The result shows that there was a significant positive relationship between religiosity and drug abuse. However, selfesteem was not statistically related to drug abuse. Additionally, religiosity and selfesteem were not related to each other. Therefore, hypothesis five is not supported.

According to a study conducted by Bhalia, Cornwell, James, and Thames titled "Relationship among Adolescent Self-Esteem, Religiosity, and Perceived Family Support" their study did not find a significant correlation between self-esteem and religiosity. In their study, students completed a questionnaire and self-esteem was graded through the Rosenberg Scale. A religiosity scale was also created. Their study is valuable to this study because it used the Rosenberg Self-Esteem scale. However, their study used a very small sample size. The sample size of this study was much larger $(n=250)$. 


\section{CONCLUSION}

In the light of the present study as discussed above, it seems justifiable to conclude as follows:

That there will be a significant influence of religiosity on substance abuse among undergraduates, there will be a significant influence of self-esteem on substance abuse among undergraduates, religiosity and self-esteem will jointly predict substance abuse among undergraduates, there will be a significant influence of sex on substance abuse among undergraduates, there will be no significant relationship between religiosity and self-esteem among undergraduates.

It should be noted that the issue of substance abuse cannot be overlooked or underestimated in the clinical, social and other various fields of psychology and society at large.

\section{RECOMMENDATIONS}

From the study we can therefore recommend that the society should be educated on the dangers involve in substance abuse that the government should try find solution to the problem of substance abuse especially among adolescent and undergraduate whose cognitive abilities are still developing.

Religiosity has been viewed, for the most part, as an individual-level variable. However, because adolescents are under the authority of their parents, their religious involvement may be dictated by their parents. As Hodge et al. (2001) pointed out, "In cases in which religious participation is seen as an expression of individual spirituality, it may be more likely to express the parents' rather than the adolescent's spirituality" . Many youths may be required, or at least strongly encouraged, to attend religious services as part of a family practice. In such cases, participation in religious services does not reflect an adolescent's spirituality or even a desire to participate in religious activities. Therefore parent shouldn't dictate religiosity to their children instead guide their children towards being religious, because not every children practising their respective religion are religious, some only feign because they are under parental custody but will be good if they can be given little freedom and watch them alongside to know what they really are so that parents will know where and how to guide them when going astray.

The researcher was opportune to hold conversations with different substance abusers about the benefit and dangers involve in the intake of substance. Most of them testified to the fact that they've try not once or twice to quit the behaviour but they always find their effort abortive, this shows that most of the abusers have the knowledge of the consequences of their action as well as the strong desire to quit but their addictive nature have been a factor making their effort to quit futile.

Finally, government should encourage non-governmental organizations, guidance and counselors and psychologist who are consultants by contributing their quotas to the society through establishment of centers which will help in educating and gives 
orientation to the society at large about the health risk involve in substance abuse and as well as the damages it brings to the society and also to help in reducing substance abuse among undergraduates.

\section{REFERENCES}

Abdullahi, S.A. (2005), "Community Based Youth Drug Abuse Prevention Strategies "in Dalhatu, S. (ed.) Eassays on Local Government Administration: Fostering Better Service Delivery, Record Keeping, Accountability and Empowerment at Local Government.

Akers, Ronald, L. (1992) Drugs, Alcohol and Society: Social Structure Process and Policy. Belmout, CA; Wadsworth.

Ayatse, J. S. (2005) Cultism in Nigerian Educational Institution. Makurdi: Oracle Business Limited.

Bandura A. (1977) Social Learning Theory. Eaglewood NJ: Prentice Hall.

Bazargan, S., Sherkat, D., \& Bazargan, M. (2004). Religion and alcohol use among African- American and Hispanic inner-city emergency care patients. Journal for the Scientific Study of Religion, 43(3), 419-428.

Baron, R. A. \& Kalsher, M. J. (2003), Psychology Person Prentice Hall. India.

Chen, C. M., Dufour, M. C., \& Ye, H. (2004/2005). Alcohol consumption among young adults ages 18-24 in the United States. Alcohol Research \& Health 28(4), 269-280.

Conger, R. D. (1994). The family context of adolescent vulnerability and resilience to alcohol. Sociological Study of Children 6: 55-86.

David, S. Derald\& Stanley, S. (1990). Understanding Abnormal Behaviour (Third Edition) Houghton Miffin Company Boston, Dallas Geneva, Illinois Palo Alto Princeton, New Jersey.

Ekejuba D. I. (1991). Drug Abuse in Nigeria and how to check it "paper presented to Medical students. Unpublished.

Eke, A. N. (1997), Socializing Influences on HIV/AIDS related risk Behaviours among Adolescents in Nigeria. Dissertation Abstracts International, 58(4): $1829-13$.

Evans, T., Cullen, F., Dunaway, R., \& Burton, V. (1995). Religion and crime reexamined: The impact of religion, secular controls, and social ecology on adult criminality. Criminology, 33(2), 195-224. 
Fatoye, F. O. \& Morakinyo, O. (2002), Substance use amount Secondary Students in Rural and Urban Communities, in South Western Nigeria. East African Medical Journal, 79(6): 229 - 305.

Festingner, L. (1954). A theory of social comparison process. Human relations; 7(2), 117140.

Glindemann, K. E., Geller, E. S., \& Fortney, J. N. (1999). Self-esteem and alcohol consumption: A study of college drinking behavior in a naturalistic setting. Journal of Alcohol and Drug Education, 45(1), 60-71.

Glindemann, K. E., Geller, E. S., \& Fortney, J. N. (1999). Self-esteem and alcohol consumption: A study of college drinking behavior in a naturalistic setting. Journal of Alcohol and Drug Education, 45(1), $\quad$ 60-71.

Hawkins, J. D. (1997) Exploring the effects of age of alcohol use initiation and psychosocial risk factors on subsequent alcohol misuse. Journal of studies on Alcohol 58(5): 280-290.

Indiana Prevention Resource Centre (IPRC) (2003), Gate Way Drugs. Retrieved on August 22nd, 2012 from www.drugs.inidiana.edu/publications/iprc /fotline/gateway.html

Kamsy, D. C. \& Wright, J. D. (1997) substance used among street children in Honduras". In S. Eristein (ed.) Special issues on substance used among homeless Immigrants and Refugee populations: An international perspective 32(7\&8) 806-827.

Kandel, D.B., \& Wu, P. (1995) The Contributions of mothers and fathers to the intergenerational transmission of cigarette smoking in adolescence. Journal of Research in Adolescence, 5 (2) 225-252.

Kaplan (1975) Leisure: Theory and Policy. John Wiley \& Sons Limited, Canada. Social Sciences: pg 444.

Maney, D. W. (1990). Predicting university students' use of alcoholic beverages. Journal of College Student Development, 331(1), 23-32.

Mersy (2003) Drugs and Alcohol use among school aged Youth American Academic Pediatrics.

Miller, W. (1998).Researching the spiritual dimensions of alcohol and other drug problems. Addiction, 93(7), 979-990

Michalak, L, Trocki, K., \& Bond, J. (2007).Religion and alcohol in the U.S. National Alcohol Survey. Drug \& Alcohol Dependence, 87, 268-280.

National Drug Law Enforcement Agency (1997).Drug Data Collection and Research. Lagos: Drug Demand Reduction unit on National Drug Law Enforcement Agency.

NSDUH (2010) Report of substance use among Black Adults.SAMHSA health Information Network. 
Okaza, J., \&Aluede, O. (2009), Drug Abuse among Students of Ambrose Alli University, Ekpoma, Nigeria. European Journal of Social Sciences, 10(1) 72 86.

Samuels, D. J. (1974). Low self-concept as a cause of drug abuse. Journal of Drug Education, 4, 421-438.

Sands, T., Archer, J., \& Puelo, S. (1998). Prevention of health-risk behaviors in college students: Evaluating seven variables. Journal of College Student Development, 39, 331-342.

Segal, B., Rhenberg, G., \& Sterling, S. (1975). Self-concept and drug and alcohol use in female college students. Journal of Alcohol and Drug Education, 20, 17-22.

Stack, S., \& Kposowa, A. (2006). The effect of religiosity on tax fraud acceptability: A cross- national analysis. Journal for the Scientific Study of Religion, 45(3), 325- 351.

Thorton, D., Arrowood, A.J. (1996). Self-evaluation, self enhancement and the locus of social comparison, Journal of Experimental Social Psychology 2: 591 605.

Parish, J. G., \& Parish, T. S. (1991). Support systems functionality, self- concepts, and alcohol use. College Student Journal, 25(4), 470-472.

Pritchard, M. E., Wilson, G. S., \& Yamnitz, B. (2007). What predicts adjustment among college students? A longitudinal panel study. Journal of American College Health, 56(1), 15-21.

Pullen, L., Modrcin-Talbott, M., West, W., \& Muenchen, R. (1999). Spiritual high vs high on spirits: Is religiosity related to adolescent alcohol and drug abuse? Journal of Psychiatric and Mental Health Nursing, 6, 3-8.

Pullen, L. N. (1994). The relationship among alcohol abuse in college students and selected psychological/demographic variables. Journal of Alcohol and Drug Education, 40(1), 36-50.

Wood, J.V., Taylor, S.E.; Lichtman, R.R. (1985). Social comparison in adjustment to breast cancer. Journal of Personality and Social 49(5): 1116-1183.

Wood, J.V. (1989). Theory and research concerning social comparisons of personal attributes psychological Bulletin 106 (2): 231-248.

Wood, R.E., Bandura, A. (1989). Social cognitive theory of organizational management. Academy of management review, 14 (3), 361-384.

Zimmerman, M. A., Copeland, L. A., Shope, J. T., \& Dielman, T. E. (1997). A longitudinal study of self-esteem: Implications for adolescent development. Journal of Youth and Adolescence, 26, 117-141.12 